\title{
The complete mitochondrial genome of Dermacentor (Indocentor) auratus (Acari, Ixodidae)
}

\author{
Jean-Marc Chavatte* and Sophie Octavia
}

National Public Health Laboratory, National Centre for Infectious Diseases, Block G, Level 13, 16 Jalan Tan Tock Seng, Singapore 308442, Singapore

Received 4 October 2020, Accepted 6 January 2021, Published online 19 January 2021

\begin{abstract}
Dermacentor (Indocentor) auratus Supino, 1897 is a prominent ixodid vector of numerous pathogens of public health and veterinary importance. Using long-range PCR of two overlapping regions sequenced on an Illumina MiSeq machine, the complete mitochondrial genome of $D$. auratus is reported here. The resulting contigs were able to be assembled into a complete and circularised genome which had the general organisation of the mitochondrial genomes of the Metastriates. It had a total length of $14,766 \mathrm{bp}$ and contained 37 genes, including 13 protein-coding genes, 22 transfer RNA genes, and 2 ribosomal RNA genes, as well as 2 non-coding control regions and 3 tick-boxes. The phylogenetic analysis on the whole mitogenome confirmed the position of $D$. auratus within the Dermacentor clade.
\end{abstract}

Key words: Dermacentor (Indocentor) auratus, Mitochondrial genome, Long-range PCR, Illumina sequencing.

\begin{abstract}
Résumé - Le génome mitochondrial complet de Dermacentor (Indocentor) auratus (Acari, Ixodidae). Dermacentor (Indocentor) auratus Supino, 1897 est un ixode, vecteur notable de nombreux pathogènes importants en santé publique et en médecine vétérinaire. Utilisant la PCR en fragment long sur deux régions chevauchantes combinée au séquençage sur une plate-forme Illumina MiSeq, le génome mitochondrial complet de D. auratus est présenté ici. Les contigs obtenus ont été assemblés en un génome circulaire complet conforme à l'organisation générale des génomes mitochondriaux des Métastriates. D'une longueur totale de $14766 \mathrm{pb}$, il contient 37 gènes, incluant 13 gènes codants des protéines, 22 gènes d'ARN de transfert et 2 gènes d'ARN ribosomaux, ainsi que 2 régions contrôles non-codantes et 3 motifs « tick-box ». L'analyse phylogénétique sur le mitogénome complet confirme la position de D. auratus au sein du clade Dermacentor.
\end{abstract}

\section{Introduction}

Ticks are the second largest pathogen transmitters globally, after mosquitoes [7], and tick-borne diseases (TBDs) have a colossal impact on livestock industries worldwide, and also constitute an important public health threat for humans [20]. The recent increase in TBD infections in the United States and globally, added to the increase travel fluxes and mobility, accentuates the risk of import of TBDs into new areas, as recently highlighted with the first imported case of human babesiosis in Singapore [15]. Following import, the risk of introduction and establishment of a TBD locally depends on the vector competency of the local tick populations. It is therefore important to inventory the tick fauna, particularly in areas where this has been overlooked or neglected [13] to perform risk assessments. Renewed interest in this field has lead to interesting reports such as the recent discovery of Dermacentor (Indocentor) auratus Supino, 1897 [24] in Singapore, from multiple hosts, including humans [14]. Dermacentor auratus is a competent vector of the highly pathogenic zoonotic

\footnotetext{
*Corresponding author: jmg_chavatte@ncid.sg
}

Kyasanur Forest disease (KFD) virus [21] and the murine Lanjan Virus [25]. Several other pathogens have also been isolated from D. auratus such as Anaplasma spp., Rickettsia spp., Francisella spp., Borrelia spp. and Hepatozoon spp. $[22,23,27]$, highlighting the veterinary and public health risks related to this species [14, 22, 23, 27].

Along with the report of the discovery of $D$. auratus in Singapore, preliminary molecular data on its mitogenome were provided with sequences of the cytochrome c oxidase I (coxl) and the large subunit ribosomal RNA (lsu $r R N A$ ) genes [14]. The sequences were deposited in GenBank under accession numbers MT371767 and MT371768 (coxl) and MT371591 and MT371592 (lsu rRNA), respectively [14] and were used as the starting point for the present work that reports the entire mitochondrial genome of $D$. auratus.

\section{Materials and methods}

DNA material from a $D$. auratus TKL1 isolate obtained in [14] was used. Assuming that the mitogenome of D. auratus is circular, similar to other Metastriate ticks, its amplification was 
Table 1. Mitochondrial genome organisation of Dermacentor auratus with gene order, positions, lengths, nucleic acid composition, coding strand, and start and stop codons.

\begin{tabular}{|c|c|c|c|c|c|c|c|c|c|}
\hline \multirow[t]{2}{*}{ Gene } & \multicolumn{2}{|c|}{ Position } & \multirow{2}{*}{$\begin{array}{c}\text { Length } \\
\text { (bp) }\end{array}$} & \multicolumn{2}{|c|}{ Nucleic acid } & \multirow{2}{*}{$\begin{array}{l}\text { Coding } \\
\text { strand }\end{array}$} & \multicolumn{2}{|c|}{ Codon } & \multirow{2}{*}{$\begin{array}{l}\text { Amino } \\
\text { acid size }\end{array}$} \\
\hline & Start & End & & AT $(\%)$ & GC $(\%)$ & & Start & Stop & \\
\hline$\overline{t R N A-M}$ & 1 & 68 & 68 & 75 & 25 & + & & & \\
\hline $\operatorname{nad} 2$ & 69 & 1028 & 960 & 83.7 & 16.3 & + & ATT & TAA & 319 \\
\hline$t R N A-W$ & 1027 & 1088 & 62 & 82.3 & 17.7 & + & & & \\
\hline tRNA-Y & 1094 & 1157 & 64 & 73.4 & 26.6 & - & & & \\
\hline $\operatorname{cox} 1$ & 1150 & 2688 & 1539 & 69.7 & 30.3 & + & ATT & TAA & 512 \\
\hline $\cos 2$ & 2693 & 3365 & 673 & 71 & 29 & + & ATG & $\mathrm{T}-$ & 224 \\
\hline tRNA-K & 3366 & 3432 & 67 & 70.1 & 29.9 & + & & & \\
\hline tRNA-D & 3433 & 3492 & 60 & 78.3 & 21.7 & + & & & \\
\hline atp 8 & 3493 & 3654 & 162 & 84.6 & 15.4 & + & ATT & TAA & 53 \\
\hline atp6 & 3648 & 4313 & 666 & 79 & 21 & + & ATG & TAA & 221 \\
\hline $\cos 3$ & 4324 & 5101 & 778 & 73.8 & 26.2 & + & ATG & $\mathrm{T}-$ & 259 \\
\hline$t R N A-G$ & 5102 & 5162 & 61 & 90.2 & 9.8 & + & & & \\
\hline nad3 & 5163 & 5507 & 345 & 80.9 & 19.1 & + & ATT & TAA & 114 \\
\hline tRNA-A & 5507 & 5570 & 64 & 79.7 & 20.3 & + & & & \\
\hline$t R N A-R$ & 5575 & 5634 & 60 & 73.3 & 26.7 & + & & & \\
\hline$t R N A-N$ & 5635 & 5697 & 63 & 76.2 & 23.8 & + & & & \\
\hline$t R N A-S 1$ & 5710 & 5765 & 56 & 82.1 & 17.9 & + & & & \\
\hline$t R N A-E$ & 5766 & 5825 & 60 & 78.3 & 21.7 & + & & & \\
\hline Tick Box 1 & 5826 & 5843 & 18 & & & - & & & \\
\hline nadl & 5844 & 6762 & 919 & 76.9 & 23.1 & - & ATT & $\mathrm{T}-$ & 306 \\
\hline$t R N A-L 2$ & 6763 & 6828 & 66 & 72.7 & 27.3 & - & & & \\
\hline Tick Box 2 & 6829 & 6846 & 18 & & & - & & & \\
\hline lsu rRNA & 6852 & 8017 & 1166 & 81.6 & 18.4 & - & & & \\
\hline$t R N A-V$ & 8018 & 8078 & 61 & 77 & 23 & - & & & \\
\hline ssu rRNA & 8079 & 8778 & 700 & 78.7 & 21.3 & - & & & \\
\hline CR1 & 8779 & 9089 & 311 & 65.9 & 34.1 & - & & & \\
\hline tRNA-I & 9090 & 9152 & 63 & 73 & 27 & + & & & \\
\hline$t R N A-Q$ & 9160 & 9225 & 66 & 84.8 & 15.2 & - & & & \\
\hline Tick Box 3 & 9229 & 9246 & 18 & & & + & & & \\
\hline$t R N A-F$ & 9257 & 9315 & 59 & 86.4 & 13.6 & - & & & \\
\hline nad5 & 9315 & 10,973 & 1659 & 79.4 & 20.6 & - & ATT & TAA & 552 \\
\hline$t R N A-H$ & 10,974 & 11,035 & 62 & 83.9 & 16.1 & - & & & \\
\hline nad4 & 11,036 & 12,350 & 1315 & 78.7 & 21.3 & - & ATG & $\mathrm{T}-$ & 438 \\
\hline $\operatorname{nad} 4 L$ & 12,344 & 12,619 & 276 & 81.5 & 18.5 & - & ATG & TAA & 91 \\
\hline tRNA-T & 12,622 & 12,682 & 61 & 85.2 & 14.8 & + & & & \\
\hline tRNA-P & 12,683 & 12,743 & 61 & 80.3 & 19.7 & - & & & \\
\hline nad6 & 12,746 & 13,180 & 435 & 83.2 & 16.8 & + & ATA & TAA & 144 \\
\hline$c y t b$ & 13,192 & 14,273 & 1082 & 73.9 & 26.1 & + & ATG & $\mathrm{TA}-$ & 360 \\
\hline$t R N A-S 2$ & 14,274 & 14,338 & 65 & 81.5 & 18.5 & + & & & \\
\hline$t R N A-L 1$ & 14,340 & 14,400 & 61 & 72.1 & 27.9 & - & & & \\
\hline $\mathrm{CR} 2$ & 14,401 & 14,704 & 304 & 66.8 & 33.2 & - & & & \\
\hline tRNA-C & 14,705 & 14,761 & 57 & 78.9 & 21.1 & + & & & \\
\hline
\end{tabular}

attempted using two long-range PCRs targeting fragments of $\approx 9700 \mathrm{bp}$ and $\approx 6200 \mathrm{bp}$ spanning the whole, and overlapping at their extremities by $457 \mathrm{bp}$ and $709 \mathrm{bp}$. The primers proposed by [4] and [9] and successfully used in [14] were cross-paired. The PCRs were run in a total volume of $30 \mu \mathrm{L}$ containing $1 \mathrm{X}$ High Fidelity PCR Buffer, $2 \mathrm{mM}$ of $\mathrm{MgSO}_{4}, 250 \mu \mathrm{M}$ of each dNTP, $250 \eta \mathrm{M}$ of each oligonucleotide primer, $0.06 \mathrm{U} / \mu \mathrm{L}$ of Platinum $^{\circledR}$ Taq High Fidelity DNA Polymerase (Invitrogen ${ }^{\mathrm{TM}}$ ) and $3 \mu \mathrm{L}$ of DNA template. The PCR assays were performed on a Veriti thermal cycler (Applied Biosystems), with the following conditions: initial denaturation at $95{ }^{\circ} \mathrm{C}$ for $2 \mathrm{~min}$, followed by 35 cycles of annealing at $55^{\circ} \mathrm{C}$ for $1 \mathrm{~min}$, extension at $68{ }^{\circ} \mathrm{C}$ for 6 or 10 min depending on the fragment size (increased by $20 \mathrm{~s}$ at each cycle from the 11 th cycle), and denaturation at $94{ }^{\circ} \mathrm{C}$ for $30 \mathrm{~s}$, then terminated with a final cycle of annealing at $55^{\circ} \mathrm{C}$ for $2 \mathrm{~min}$ and extension at $72{ }^{\circ} \mathrm{C}$ for $15 \mathrm{~min}$.

PCR products were visualised by capillary electrophoresis on a QIAxcel ${ }^{\circledR}$ Advanced System (QIAgen ${ }^{\circledR}$ ) equipped with a QIAxcel ${ }^{\circledR}$ DNA High Resolution Kit $\left(\right.$ QIAgen $\left.^{\circledR}\right)$, then purified using a QIAquick ${ }^{\circledR}$ PCR Purification Kit (QIAgen ${ }^{\circledR}$ ), eluted in $\mathrm{EB}$ and stored at $-30{ }^{\circ} \mathrm{C}$ until sequencing. Both fragments were prepared for next-generation sequencing (NGS) by a Nextera XT DNA Library Preparation Kit (Illumina $^{\mathrm{TM}}$ ) and sequenced on a MiSeq System (Illumina ${ }^{\mathrm{TM}}$ ) to generate $300 \mathrm{bp}$ paired-end reads. Fastq raw reads were trimmed using Trimmomatic v.0.36 [5] to remove low-quality bases and assembled with Shovill v.1.0.4 with SPAdes as the 


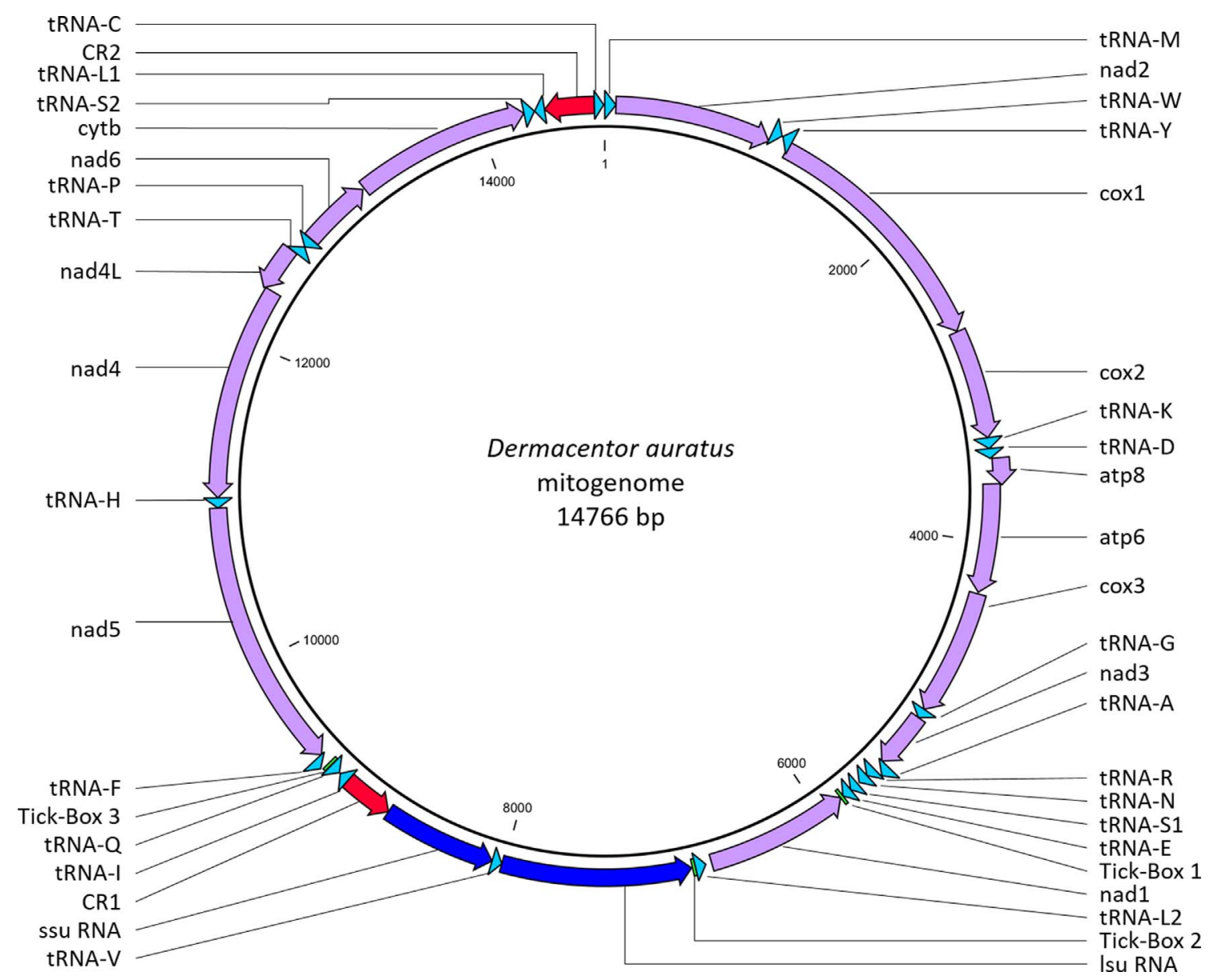

Figure 1. Map of the mitochondrial genome of Dermacentor (Indocentor) auratus. Protein coding genes in purple; ribosomal RNA genes in dark blue; transfer RNA genes in light blue; control regions in red, and tick-boxes in green.

assembler [1]. Contigs were aligned and scaffolded using the overlapping fragments to reconstruct the full mitogenome of D. auratus using CLC Main Workbench v8.0.1 (QIAgen ${ }^{\circledR}$ ). Annotation was performed using MITOS [3] and manual search of homology and comparison. Transfer RNA secondary structure prediction was obtained using the Vienna RNA Websuite [10]. Multiple alignments of the D. auratus mitochondrial genomes obtained in this study with several mitogenomes (39 Ixodidae, 1 Argasidae and 1 Nuttalliellidae) retrieved from GenBank were performed with MUSCLE [8]. Phylogenetic analysis, performed with MEGAX [12], was inferred by the maximum likelihood (ML) method based on the GTR + $\Gamma+$ I model of evolution [26]. The most appropriate model of nucleotide substitution was selected based on BIC score [19]. Reliability of tree topology, branch support and nodal robustness were assessed by non-parametric bootstrap using 1000 replicates.

The mitochondrial genome sequence obtained in this study was deposited in GenBank under accession number MW034677.

\section{Results and discussion}

Long-range PCRs, sequencing, and de novo assemblies generated 2 contigs of $9700 \mathrm{bp}$ and $6194 \mathrm{bp}$, respectively with an average sequencing depth of 25- and 44-fold coverage, respectively. After reconstruction, the complete mitogenome of $D$. auratus was confirmed to be circular and showed a total length of $14,766 \mathrm{bp}$, with AT/GC contents of $77.2 \%$ and $22.8 \%$, respectively. Genome annotation revealed homology to the other hard-tick mitochondrial genomes, where it contained 37 genes, including 13 protein-coding genes (coxl to cox3, nadl to nad6, nad4L, atp6, atp8 and cytb), 22 transfer RNA genes (tRNAs), 2 ribosomal RNA genes (rRNAs), as well as 2 non-coding control regions (CR) and 3 tick-boxes. Details about the organisation, orientation and size of the genes and non-coding elements are listed in Table 1 and mapped in Figure 1.

The complete and annotated mitochondrial genome of D. auratus has been deposited in GenBank under the accession number MW034677.

\section{Protein coding genes}

Six of the protein-coding genes were initiated with an ATG codon (cox2, atp6, cox3, nad4, nad4L and cytb), six with an ATT codon (nad1, nad2, cox1, atp8, nad3 and nad5), and one with an ATA codon (nad6). Eight of the protein-coding genes were terminated with the standard TAA codon (nad2, cox1, atp8, atp6, nad3, nad5, nad4L and nad6), and five with 

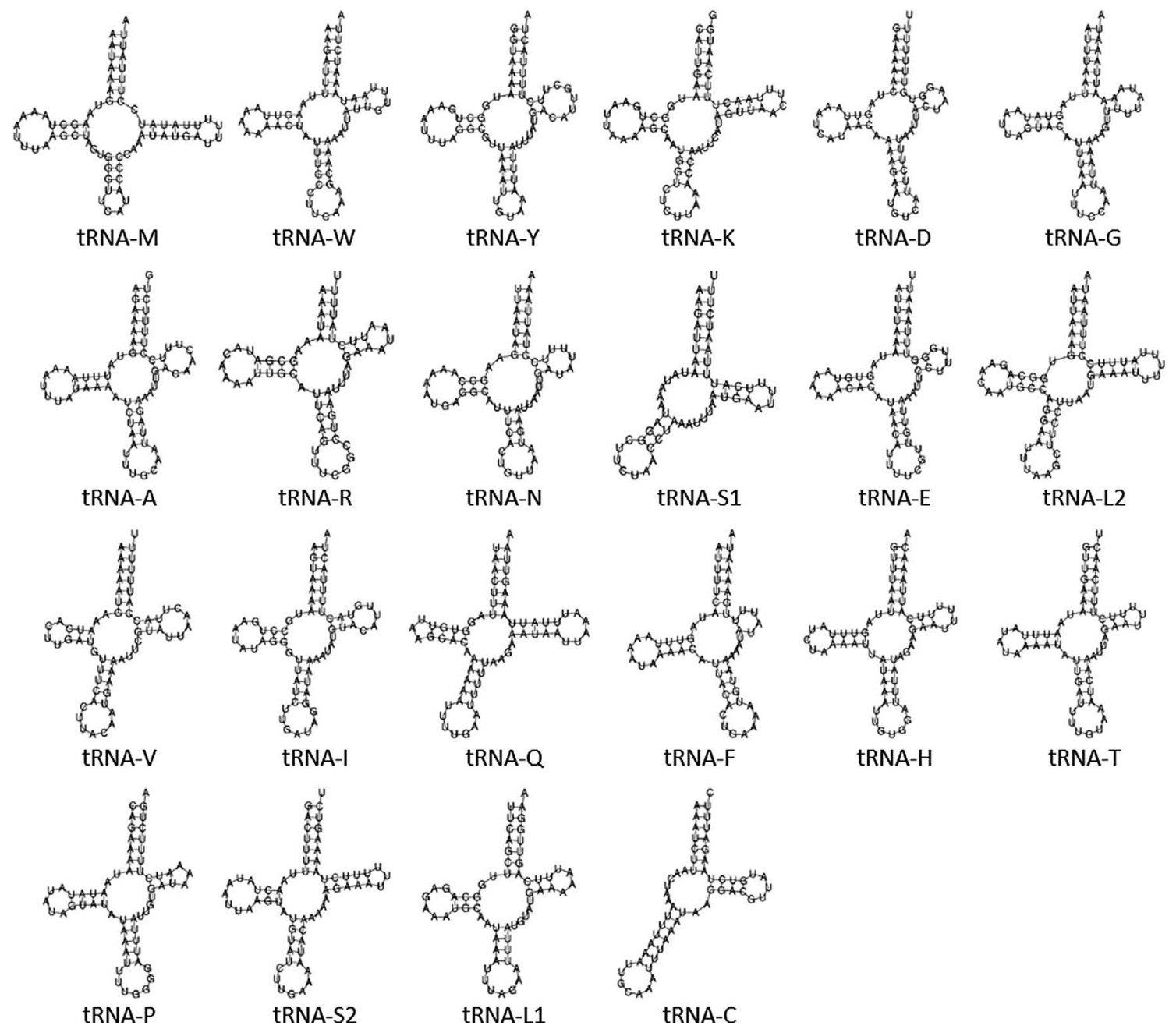

Figure 2. Predicted secondary structure of the mitochondrial tRNA genes of Dermacentor (Indocentor) auratus obtained using the Vienna RNA Websuite [10].

the truncated termination codons TA- (cytb) and $\mathrm{T}-(\operatorname{cox} 2$, cox3, nadl and nad4). Alternative start codons and truncated stop codons $\mathrm{T}-$ or TA - have been found in the mitogenomes of other Dermacentor species [11], other ticks [6, 16, 18, 28], and spiders [17]. The truncated stop codons are completed by polyadenylation of the mature transcript [18]. The length of the protein-coding genes ranged from $162 \mathrm{bp} \mathrm{(atp8)} \mathrm{to}$ 1659 bp (nad5), and their AT/GC contents range from $69.7 \% / 30.3 \%$ (coxl) to $84.6 \% / 15.4 \%$ (atp 8 ). Nine of the protein-coding genes (nad2, coxl, cox2, atp8, atp6, cox3, nad3, nad6 and cytb) were encoded on the positive strand, while the remaining four (nad1, nad4, nad4L and nad5) were encoded on the negative strand.

\section{Ribosomal RNA genes}

Both ssu rRNA and lsu rRNA genes were found with a length of $700 \mathrm{bp}$ and $1166 \mathrm{bp}$, respectively similar to other ticks $[6,11,16,18,28]$. Their AT/GC compositions were $78.7 \% / 21.3 \%$ and $81.6 \% / 18.4 \%$ for ssu rRNA and $l s u$ rRNA, respectively. They were both located on the negative strand between the $t R N A-L 2$ gene and the CR1 with the $t R N A-V$ gene intercalated in between, this organisation follows the other Metastriates [18] (Fig. 1).

\section{Transfer RNA genes}

Twenty two $t R N A$ genes were identified including $2 t R N A-L$ and 2 tRNA-S (Figs. 1, 2). Their size ranged from $56 \mathrm{bp}$ (tRNA-S1) to 68 bp ( $t R N A-M)$ (Table 1). The majority of the tRNA genes ( $t R N A-M, t R N A-W, t R N A-K, t R N A-D, t R N A-G$, tRNA-A, tRNA-R, tRNA-N, tRNA-SI, tRNA-E, tRNA-I, tRNA-T, $t R N A-S 2$ and $t R N A-C$ ) were encoded on the positive strand, while the remaining eight were encoded on the negative strand (Fig. 1). The AT/GC content of the tRNAs ranged from $70.1 \% / 29.9 \%(t R N A-K)$ to $90.2 \% / 9.8 \%(t R N A-G)$. Prediction of the tRNA secondary structure showed that 20 of the tRNAs have the standard cloverleaf structure, while tRNA-S1 (anticodon TCT) and tRNA-C were missing the D-arm (Fig. 2). Mitochondrial tRNA-S secondary structure lacking the $\mathrm{D}$-arms is a common feature in most animal species, including ticks [28]. Mitochondrial tRNA-C secondary structures are variable among tick species with some missing D-arm and/or T-arm and some having standard cloverleaf 


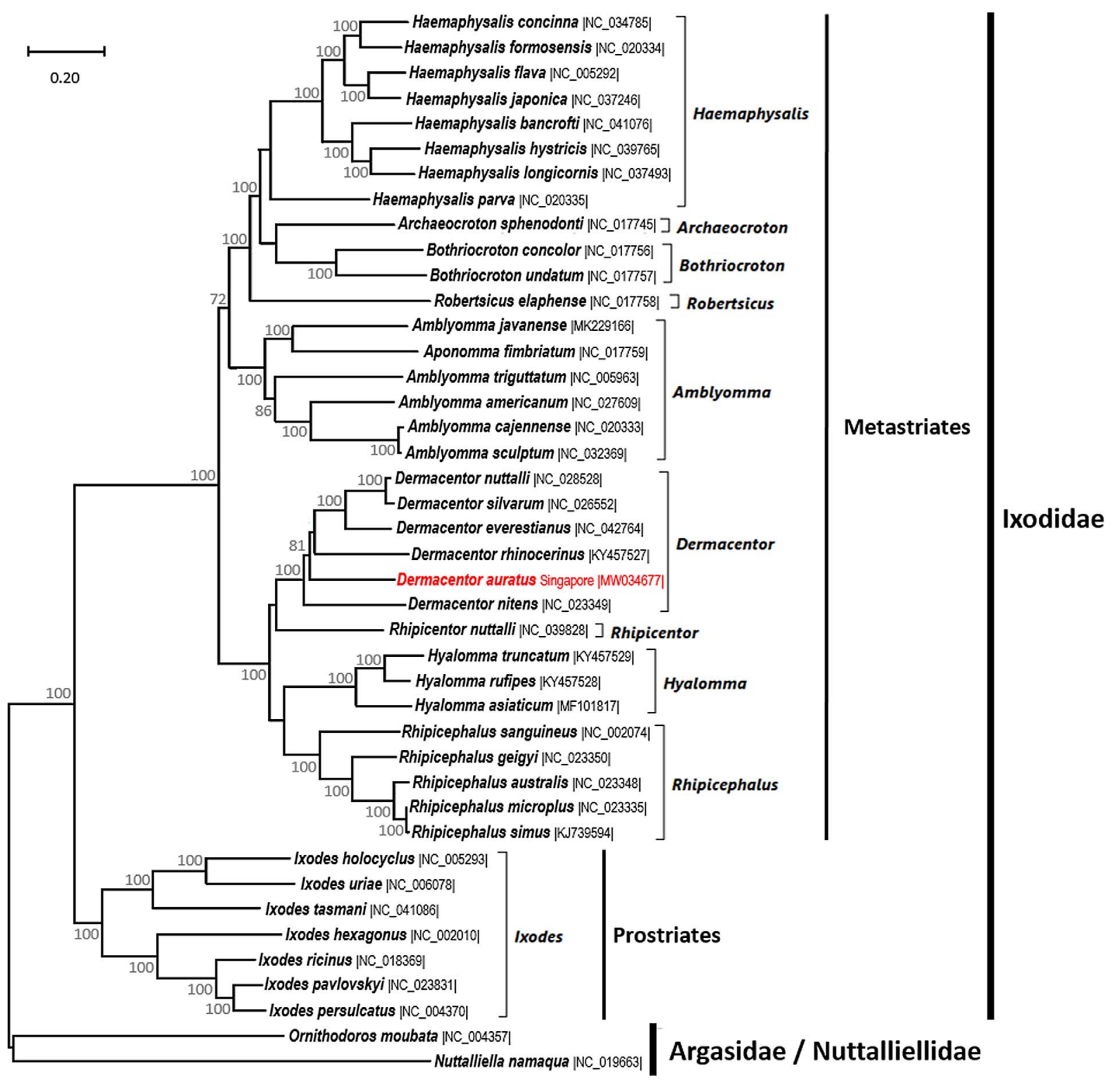

Figure 3. Maximum likelihood phylogeny inferred on the mitochondrial genomes of Dermacentor (Indocentor) auratus obtained in this study (MW034677) (highlighted) and 41 other tick mitochondrial genomes retrieved from GenBank. Accession numbers of the sequences are provided between vertical bars. The mitogenomes of the Argasidae and Nuttalliellidae were used as outgroups to root the tree. The ML analysis used the GTR $+\Gamma+$ I model of evolution [26]. Reliability of tree topology, branch support and nodal robustness were assessed by non-parametric bootstrap using 1000 replicates (only $>70 \%$ shown). Analysis performed with MEGA X [12].

structure; D. auratus was only lacking the D-arm, a feature previously observed in other tick species [27, 28] (Fig. 2). The sizes, coding strand and arrangement of the $t R N A$ genes were similar to what is observed in the mitogenome of other Dermacentor species [11] and other ticks [6, 16, 18, 28].

\section{Non-coding sequences}

Duplicate CRs were found; they contained the regulatory elements of mitochondrion transcription and replication. CR1 and CR2 spanned $311 \mathrm{bp}$ and $304 \mathrm{bp}$ in length, respectively and shared a common identical core sequence of 249 bp (position 9080-8832 for CR1 and 14692-14444 for CR2). Their AT/GC content was $65.9 \% / 34.1 \%$ and $66.8 \% / 33.2 \%$, respectively on their full length and $64.3 \% / 35.7 \%$ for the core sequence. CR1 was located between $s s u$ rRNA and $t R N A-I$ and CR2 between $t R N A-L 1$ and $t R N A-C$, both on the negative strand. These locations have been observed in many other Metastriates [6,16,18,28]. Three non-coding motifs called "tick-boxes" were identified, a number identical to what was reported in Metastriates [18]. They are short post-transcriptional regulatory elements of $18 \mathrm{bp}$ [18]. Tick-Boxes 1 and 2 shared an identical sequence, while Tick-Box 3 showed only 1 nucleotide difference. Tick-Box 1 was located on the negative strand at the 
$3^{\prime}$ end of the $\operatorname{nadl}$ gene, a position widely overlooked in many published tick mitochondrial genomes where the termination of the nadl gene is extended to a full TAA stop codon and abuts or overlaps with the $t R N A-E$ gene incorporating Tick-Box 1 , as pointed out by [18]. Tick-Box 2 was located between the $l s u$ $R N A$ and the $t R N A-L 2$ genes on the negative strand, while Tick-Box 3 was located between $t R N A-Q$ and $t R N A-F$ on the positive strand, following the general organisation of the other Metastriates [18].

\section{Phylogenetic analysis}

The ML analysis was performed on the mitochondrial genomes of D. auratus obtained in this study (MW034677) and 39 other Ixodidae, as well as 1 Argasidae and 1 Nuttalliellidae used as outgroups to root the tree (Fig. 3). The phylogenetic tree of the Ixodidae was strongly supported with the major genera clearly separated (bootstrap values 100\%) (Fig. 3) and was monophyletic, following the recent establishment of the genera Robersticus and Archaeocroton to accommodate Amblyomma elaphense and Amblyomma sphenodonti [2], which previously had controversial phylogenetic positions (Fig. 3) [2, 6, 16, 28]. Expectedly, D. auratus is clustered among the other Dermacentor species (Fig. 3).

\section{Dermacentor subgenera}

Up to seven subgenera were recognised within the genus Dermacentor: Dermacentor, Indocentor, Asiacentor, Americentor, Serdjukovia, Kohlsiella and Olenvenia, with the validity of the last three remaining controversial [29]. The type species of the subgenus Indocentor is D. auratus. The mitochondrial genome of $D$. auratus obtained here constitutes a useful reference for future studies on Dermacentor subgeneric classification. This will become particularly true when more sequences from different species become available, and reaching this point could be accelerated with the use of the simple protocol adopted here.

\section{Conclusion}

This study reports the complete mitochondrial genome of D. (Indocentor) auratus obtained using a simple method of amplification and sequencing based on two long-range PCRs and next generation sequencing. The mitogenome of $D$. auratus is circular and has the typical Metastriates tick mitochondrial genome organisation. All the genes were annotated and the secondary structure of the tRNAs was determined. Phylogenetic analyses indicated that $D$. auratus clustered with other Dermacentor species. The availability of the complete mitochondrial genome sequence of $D$. auratus will provide a useful reference to help in the rapid and accurate identification of this important vector of TBDs, as well as for further studies on the phylogeny and evolution history of hard ticks.

Acknowledgements. The authors are grateful to Dr Chew Ka Lip who collected the specimen and Dr Kwak Mackenzie who contributed to its identification. The authors declare that they have no conflict of interest.

\section{References}

1. Bankevich A, Nurk S, Antipov D, Gurevich AA, Dvorkin M, Kulikov AS, Lesin VM, Nikolenko SI, Pham S, Prjibelski AD, Pyshkin AV, Sirotkin AV, Vyahhi N, Tesler G, Alekseyev MA, Pevzner PA. 2012. SPAdes: A new genome assembly algorithm and its applications to single-cell sequencing. Journal of Computational Biology, 19, 455-477.

2. Barker SC, Burger TD. 2018. Two new genera of hard ticks, Robertsicus n. gen. and Archaeocroton n. gen., and the solution to the mystery of Hoogstraal's and Kaufman's "primitive" tick from the Carpathian Mountains. Zootaxa, 4500(4), 543-552.

3. Bernt M, Donath A, Jühling F, Externbrink F, Florentz C, Fritzsch G, Pütz J, Middendor M, Stadler PF. 2013. MITOS: Improved de novo Metazoan mitochondrial genome annotation. Molecular Phylogenetics and Evolution, 69, 313-319.

4. Black WC IV, Piesman J. 1994. A phylogeny of hard and soft tick taxa based on mitochondrial 16S ribosomal DNA sequences. Proceedings of the National Academy of Sciences of the United States of America, 91, 10034-10038.

5. Bolger AM, Lohse M, Usadel B. 2014. Trimmomatic: a flexible trimmer for Illumina sequence data. Bioinformatics, 30, 2114-2120.

6. Burger TD, Shao R, Beati L, Miller H, Barker SC. 2012. Phylogenetic analysis of ticks (Acari: Ixodida) using mitochondrial genomes and nuclear rRNA genes indicates that the genus Amblyomma is polyphyletic. Molecular Phylogenetics and Evolution, 64, 45-55.

7. De la Fuente J, Estrada-Peña A, Venzal JM, Kocan KM, Sonenshine DE. 2008. Overview: ticks as vectors of pathogens that cause disease in humans and animals. Frontiers in Bioscience, 13, 6938-6946.

8. Edgar RC. 2004. MUSCLE: multiple sequence alignment with high accuracy and high throughput. Nucleic Acids Research, 32, 1792-1797.

9. Folmer O, Black M, Hoeh W, Lutz R, Vrijenhoek R. 1994. DNA primers for amplification of mitochondrial cytochrome $c$ oxidase subunit I from diverse metazoan invertebrates. Molecular and Marine Biology and Biotechnology, 3, 294-299.

10. Gruber AR, Lorenz R, Bernhart SH, Neuböck R, Hofacker IL. 2008. The Vienna RNA Websuite. Nucleic Acids Research, 36, W70-W74.

11. Guo DH, Zhang Y, Fu X, Gao Y, Liu YT, Qiu JH, Chang QC, Wang CR. 2016. Complete mitochondrial genomes of Dermacentor silvarum and comparative analyses with another hard tick Dermacentor nitens. Experimental Parasitology, 169, 22-27.

12. Kumar S, Stecher G, Li M, Knyaz C, Tamura K. 2018. MEGA $\mathrm{X}$ : molecular evolutionary genetics analysis across computing platforms. Molecular Biology and Evolution, 35, 1547-1549.

13. Kwak ML. 2018. Ticks in the Lion City: a preliminary review of the tick fauna of Singapore. Experimental and Applied Acarology, 76(2), 263-267.

14. Kwak ML, Chavatte J-M, Chew KL, Lee BPY-H. 2021. Emergence of the zoonotic tick Dermacentor (Indocentor) auratus Supino, 1897 (Acari: Ixodidae) in Singapore. Ticks and Tick-borne Diseases, 12, 101574.

15. Lim P-L, Chavatte J-M, Vasoo S, Yang J. 2020. Imported human babesiosis, Singapore, 2018. Emerging Infectious Diseases, 26(4), 826-828.

16. Liu GH, Chen F, Chen YZ, Song HQ, Lin RQ, Zhou DH, Zhu XQ. 2013. Complete mitochondrial genome sequence data provides genetic evidence that the brown dog tick Rhipicephalus sanguineus (Acari: Ixodidae) represents a species complex. International Journal of Biological Sciences, 9, e361-e369. 
17. Masta SE, Boore JL. 2004. The complete mitochondrial genome sequence of the spider Habronattus oregonensis reveals rearranged and extremely truncated tRNAs. Molecular Biology and Evolution, 21, e893-e902.

18. Montagna M, Sassera D, Griggio F, Epis S, Bandi C, Gissi C. 2012. Tick-box for $3^{\prime}$-end formation of mitochondrial transcripts in Ixodida, basal chelicerates and Drosophila. PLoS One, 7, e47538.

19. Schwarz GE. 1978. Estimating the dimension of a model. Annals of Statistics, 6, 461-464.

20. Sonenshine DE. 2018. Range expansion of tick disease vectors in North America: implications for spread of tick-borne disease. International Journal of Environmental Research and Public Health, 15, 478.

21. Sreenivasan MA, Bhat HR, Naik SV. 1979. Experimental transmission of Kyasanur Forest disease virus by Dermacentor auratus Supino. Indian Journal of Medical Research, 69, 701-707.

22. Sumrandee C, Baimai V, Trinachartvanit W, Ahantarig A. 2015. Hepatozoon and Theileria species detected in ticks collected from mammals and snakes in Thailand. Ticks and Tick-borne Diseases, 6, 309-315.

23. Sumrandee C, Baimai V, Trinachartvanit W, Ahantarig A. 2016. Molecular detection of Rickettsia, Anaplasma, Coxiella and
Francisella bacteria in ticks collected from Artiodactyla in Thailand. Ticks and Tick-borne Diseases, 7, 678-689.

24. Supino F. 1897. Nuovi Ixodes della Birmania (nota preventiva). Atti della Societá Veneto-Trentina di Scienze Naturali Residente in Padova, Serie, 2(3), 230-238.

25. Tan DS, Smith CEG, McMahon DA, Bowen ETW. 1967. Lanjan virus, a new agent isolated from Dermacentor auratus in Malaya. Nature, 214, 1154-1155.

26. Tavaré S. 1986. Some probabilistic and statistical problems in the analysis of DNA sequences in lectures on mathematics in the life sciences. American Mathematical Society, 17, 57-86.

27. Taylor AJ, Vongphayloth K, Vongsouvath M, Grandadam M, Brey PT, Newton PN, Sutherland IW, Dittrich S. 2016. Largescale survey for tickborne bacteria, Khammouan Province, Laos. Emerging Infectious Diseases, 22(9), 1635.

28. Williams-Newkirk AJ, Burroughs M, Changavil SS, Dash GA. 2015. The mitochondrial genome of the lone star tick (Amblyomma americanum). Ticks and Tick-Borne Diseases, 6, e793-e801.

29. Yi S, Xu R-M. 2013. The genus Dermacentor and the subgenus Indocentor (Acari: Ixodidae) from China. Oriental Insects, 47, $155-168$.

Cite this article as: Chavatte J-M, \& Octavia S. 2021. The complete mitochondrial genome of Dermacentor (Indocentor) auratus (Acari, Ixodidae). Parasite 28, 6.

\section{-0 PARASTE}

An international open-access, peer-reviewed, online journal publishing high quality papers on all aspects of human and animal parasitology

Reviews, articles and short notes may be submitted. Fields include, but are not limited to: general, medical and veterinary parasitology; morphology, including ultrastructure; parasite systematics, including entomology, acarology, helminthology and protistology, and molecular analyses; molecular biology and biochemistry; immunology of parasitic diseases; host-parasite relationships; ecology and life history of parasites; epidemiology; therapeutics; new diagnostic tools.

All papers in Parasite are published in English. Manuscripts should have a broad interest and must not have been published or submitted elsewhere. No limit is imposed on the length of manuscripts.

Parasite (open-access) continues Parasite (print and online editions, 1994-2012) and Annales de Parasitologie Humaine et Comparée (1923-1993) and is the official journal of the Société Française de Parasitologie. 